\title{
Asparagine Measurement
}

National Cancer Institute

\section{Source}

National Cancer Institute. Asparagine Measurement. NCI Thesaurus. Code C122096.

The determination of the amount of asparagine present in a sample. 